\title{
Chapter 18 \\ Impressions of the Students Who Participated in the Radioactivity Monitoring System of Farmland
}

\author{
Volodymyr Ganzha, Keiji Kanamori, Hana Fujimoto, and Ryo Itakura
}

\begin{abstract}
This chapter conveys the sense of crisis and mission felt by students who participated in the development of a radioactivity monitoring system that now covers each farm field to help the farmland to recover so that farming could resume. Also, it depicts the students' hard work in severe conditions and their interactions and shared feelings with the local people.
\end{abstract}

Keywords Radioactive contamination - Radioactivity monitoring system • Resuming farming

\subsection{Meeting Cheerful Farmers and Finding a Second Home}

Volodymyr Ganzha

Embassy of Japan in Ukraine,

4, Muzeiny Lane, Kyiv 01901, Ukraine

e-mail: volodymyr2009@ hotmail.com

I am conducting research on recovery measures implemented for Ukraine's agriculture and forestry industries in response to radioactive contamination, and I hope to obtain results that will also aid recovery in Fukushima. Doing so requires not only that I read books and other written materials, but also that I travel to the disaster sites repeatedly to talk to the farmers, analyzing the information I gather from a variety of sources to develop new theories and study the validity of existing theories.

\footnotetext{
V. Ganzha $(\bowtie)$

Embassy of Japan in Ukraine, 4, Muzeiny Lane, Kyiv 01901, Ukraine

e-mail: volodymyr2009@hotmail.com

K. Kanamori • H. Fujimoto • R. Itakura

Department of International Biobusiness Studies, Tokyo University of Agriculture,

1-1-1 Sakuragaoka, Setagaya-ku, Tokyo 156-8502, Japan
} 


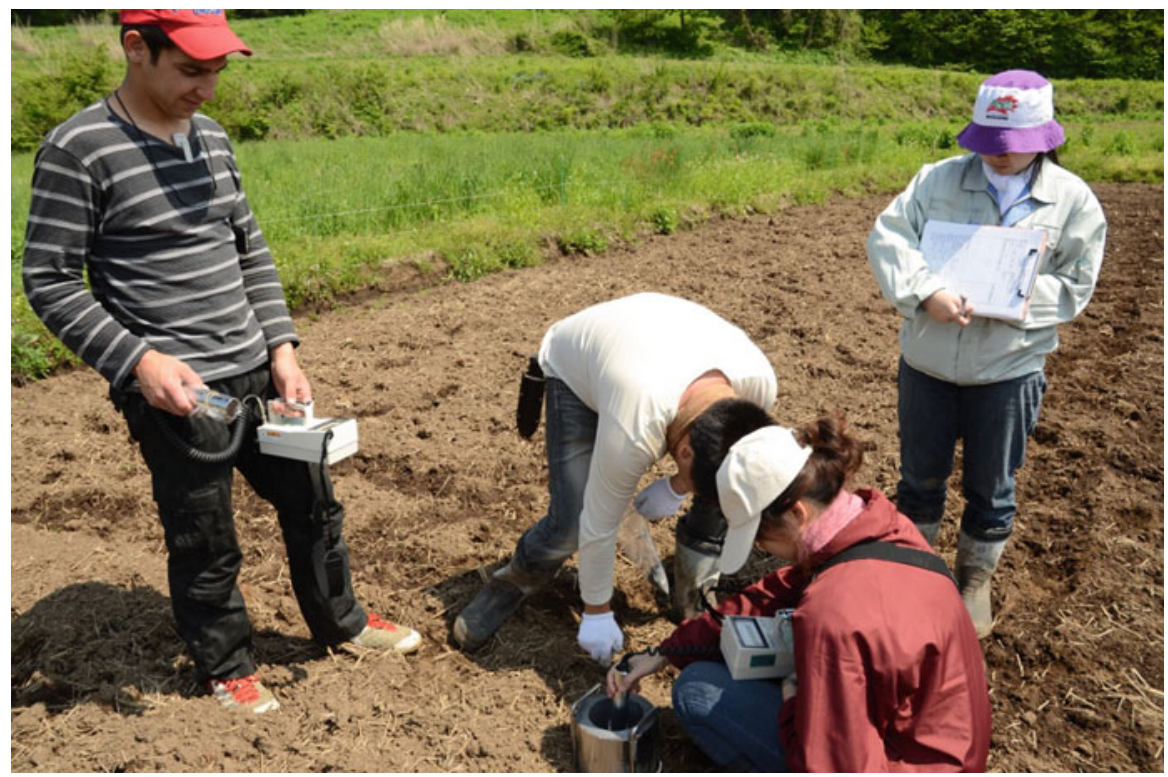

Measuring the surface dose of soil and space dose

Although I do not remember exactly how many times I have visited Soma's Tamano district since April 2012, I think it has been at least ten times. During 2012, in particular, I often participated in studies to develop a monitoring system for radioactive materials in the farmland of Tamano. Measuring radiation levels in the pastures there involved tramping around a large area of sloping land carrying a lead shielding cylinder for blocking background ambient radiation that weighed around $20 \mathrm{~kg}$. It was exhausting work, but despite the difficulties, we also had plenty of fun moments. The farmers would give us tempting homemade snacks, and on hot days they would often provide us with cold drinks. I really enjoyed that part of it.

Our group had no knowledge of the local geography, so at the outset of the monitoring study the officials who headed each of the four areas within Tamano kindly guided us around each area. They told us who owned and farmed each plot of land, its size, and the history of the crops grown on it. I was surprised at how much they knew about the land use and agriculture in their areas; they were like walking encyclopedias.

During the study we cooked our own breakfast, lunch, and dinner. Preparing and eating our meals together helped us develop a stong sense of camaraderie, and I felt that I understood what Japanese people mean when they talk about relationships forged by "sharing rice from the same pot." As a non-Japanese who had lived mainly in Tokyo, it was difficult for me to understand everything the farmers in Tamano were saying in their local dialect, but their warm smiles, mannerisms, and gentle way of speaking reminded me of farmers in my homeland of Ukraine. 
I think that if there is anything a Ukrainian such as myself can do to make a meaningful contribution to recovery from the Great East Japan Earthquake, it is to communicate as accurately as possible the initiatives taken in Ukraine and Belarus in response to the Chernobyl nuclear accident, and the problems still faced there. This is the aim I have in mind as I work on my research.

\subsection{Realization That Recovery Is a Long, Repetitive Process}

Keiji Kanamori

Department of International Biobusiness Studies, Tokyo University of Agriculture, 1-1-1 Sakuragaoka, Setagaya-ku, Tokyo 156-8502, Japan

After the Great East Japan Earthquake I wanted to do something-felt that I had to do something-for the Tohoku region where I grew up. But what practical steps should I take to help Tohoku? What could I do? I wrestled with these thoughts, unable to take action. Then, when I entered my third year and joined Professor Toshiyuki Monma's research group, he told me that the university was conducting a disaster recovery project in the city of Soma in Fukushima Prefecture. "This is it!" I thought, and made up my mind to join in.

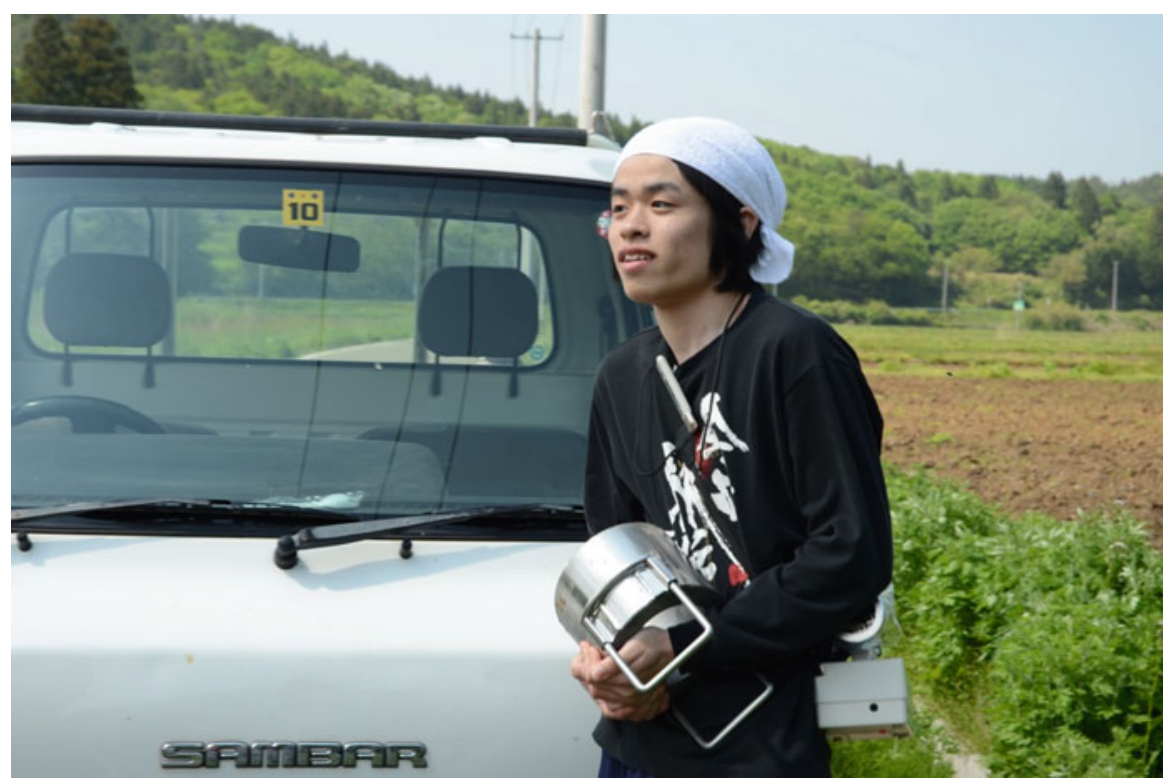

Transportation of shielding tool of lead in excess of $20 \mathrm{~kg}$ is hard work 
The site I visited was the Tamano district of Soma, located next to litate, a village designated as an evacuation zone. My first assignment was measuring radiation levels in Tamano's cultivated land, field by field. We took turns lugging around a 20-kg lead shielding cylinder and measuring the radiation dose inside it. In each field, we measured radiation levels at $1 \mathrm{~m}$ and $10 \mathrm{~cm}$ above the soil, also taking other measurements such as the depth of the topsoil. It was hard work hauling the 20-kg shielding cylinder around the steep grassland slopes and sprawling fields as we went. The slow, laborious process continued until evening, and by the time we had finished my entire body was exhausted. I remember how good Professor Monma's Thai curry tasted that night.

After we finished measuring the ambient radiation dose in the fields, our next task was collecting soil samples from each field and measuring the radioactive substances they contained. The process of drying the collected samples, breaking the clumps into fine dirt, and running them through the measuring machine was very long and arduous. During the process we had to sit in one place and just pound sample after sample into small pieces using hammers. Dust from the crushed soil would get in our mouths, and I found it really tough as I am not good at sitting still.

I had imagined that radiation testing was a difficult process requiring highly sophisticated machinery. In actual fact, however, it proved to be a slow, repetitive process that required us to physically walk around each field measuring the radiation dose, as well as to collect samples and prepare them for testing. I realized that the best way to approach the recovery effort is to just build up gradually by repeating small tasks such as these.

\subsection{Farmers' Hard Work Ruined: The Pain of Reputation- Based Damage}

Hana Fujimoto

Department of International Biobusiness Studies, Tokyo University of Agriculture, 1-1-1 Sakuragaoka, Setagaya-ku, Tokyo 156-8502, Japan

This was the second time I had visited Soma in Fukushima Prefecture as a volunteer. The first was in September 2011, 6 months after the Great East Japan Earthquake. The local nashi (Asian pear) farmers faced a labor shortage because of the earthquake and associated disasters, and I helped them to thin their crop. At that time, the farmers told me that what worried them most was whether the pears they had worked to grow would sell in the wake of the Fukushima Daiichi nuclear accident. Then, in June 2012, more than a year after the disasters, the university began measuring radiation levels in the Tamano district to develop decontamination measures. I volunteered to participate. 


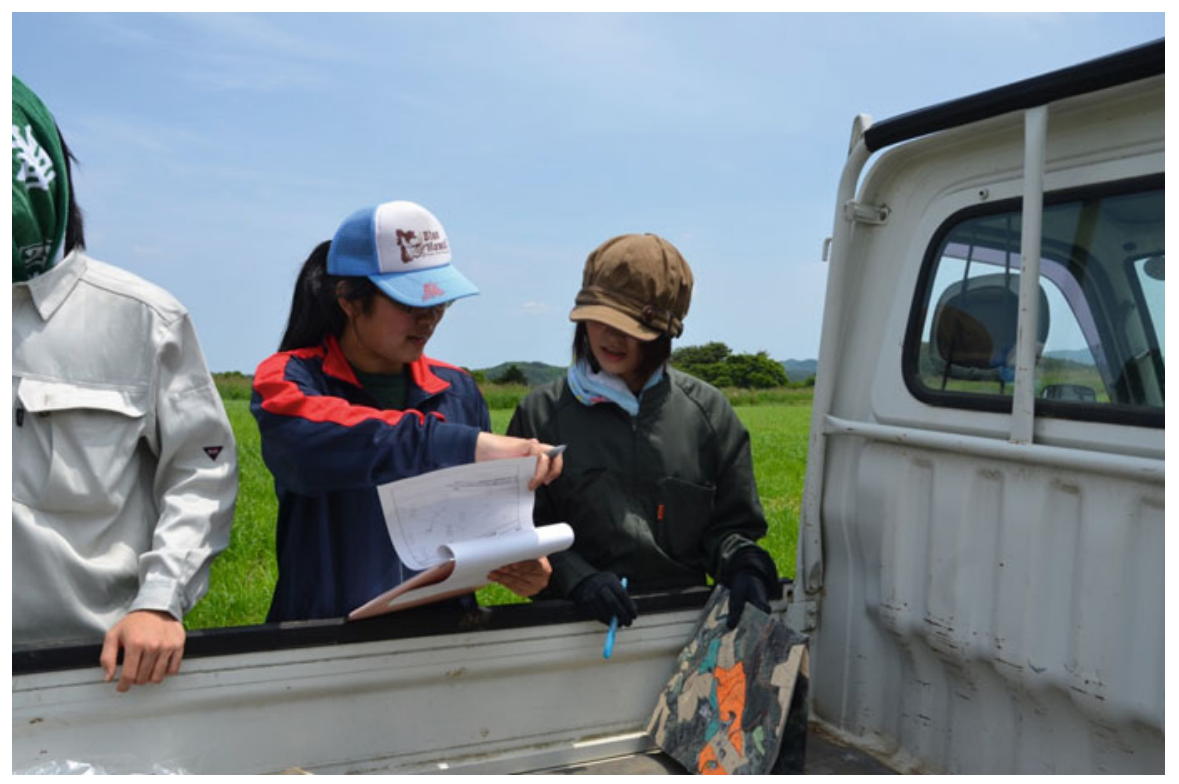

Checking the field position is one of the important tasks

Soma's Tamano district is located next to the village of Iitate, which was completely evacuated after high levels of radiation were found. The government had prohibited any planting of rice crops for consumption in the area during 2012. So, to be honest, I was anxious until I actually traveled to the site. What was it like in a high-radiation area? I imagined that the residents wore face masks all the time, that people were scared of venturing outdoors, and that the whole region was desolate and empty. But I was relieved to find that everyday life continued more normally than I had expected. At the same time, however, I noticed that the pastures had been left to run wild and were overrun with growth. Seeing this made me realize how severe the radioactive contamination had been and how much the local farmers had suffered.

In my opinion, the biggest current hurdle to recovery from the disasters is the problem of economic damage from a negative reputation. It was when we sold the Soma Revival Rice that I really felt this firsthand. Soma Revival Rice is grown in severely tsunami-damaged paddies in Soma's Iwanoko district after cleansing the soil using a salt removal method christened the Tokyo University of Agriculture Method. The rice had been tested with a germanium semiconductor detector and confirmed safe for consumption. As we offered it for sale, many people were positive, saying that they wanted to help Fukushima to recover and were willing to eat the rice if it was safe. Others, however, said that even if it had tested safe, they did 
not want to buy it because it was from Fukushima and they still felt uneasy. As this experience shows, the unease toward agricultural products from Fukushima and the associated reputation-based damage remains, even more than 2 years after the accident.

The farmers of Fukushima are investing painstaking care in decontaminating the area and ensuring the crops meet radiation limits before finally sending them to market. They are passionate about their profession, saying they do not care if their crops sell for far less than they used to, just so long as people eat them. This is why it saddens me to see people look at the crops these farmers have put their hearts into growing and say "I'm not buying it if it's from Fukushima," or "Even if it meets the official safety limit, it's still not safe." Rather than simply saying that Fukushima is dangerous, I wish people would ask themselves what we should do about it. I wish people would stop destroying the hopes of producers, who have worked even harder than usual from a desire to see people eat and enjoy produce that meets the required safety limits.

Tamano is a fantastic place developed over the years by wonderful people. When we were there, measuring the radiation in each field, we needed information such as details of the sites, the plot sizes, and the owners' names. The officials and farmers of each area in Tamano accompanied us in the searing heat as we worked, patiently explaining what we needed to know at each site. They would always provide us with plenty of drinks, telling us not to get heatstroke, and when we visited their homes to eat lunch, they would welcome our dirt-encrusted team with a smile. That is why I have decided to provide what assistance I can so that the residents of Tamano may plow their paddies and fields with peace of mind, and resume living the life to which they are accustomed.

\title{
18.4 "I Want to Farm Again": The Farmer's Words I Can't Forget
}

\author{
Ryo Itakura \\ Department of International Biobusiness Studies, \\ Tokyo University of Agriculture, 1-1-1 Sakuragaoka, \\ Setagaya-ku, Tokyo 156-8502, Japan \\ I have participated in the Soma Project on three occasions to date. These experi- \\ ences have been more valuable than I ever could have imagined and have had a \\ major influence on my life at the university.
}




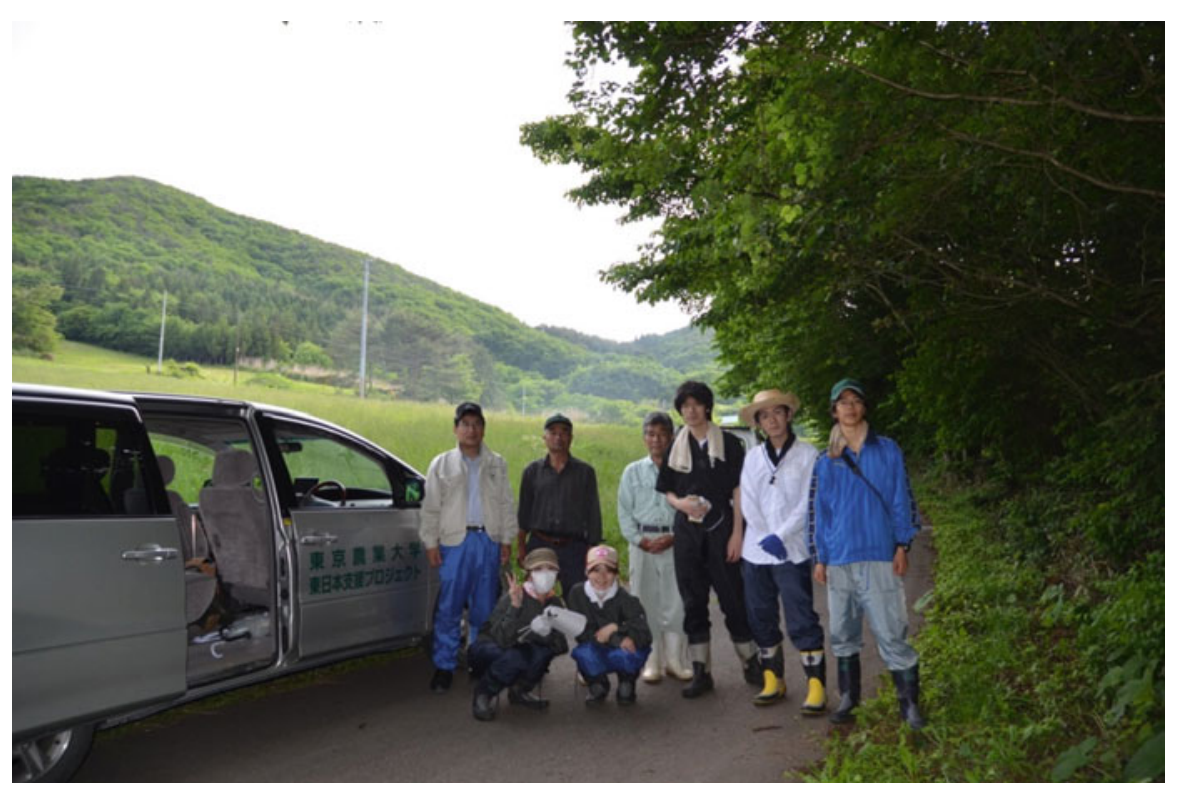

Students rest in the shade of a tree

The first two times I helped with the assistance activities, it was before the radioactive contamination had been removed, which meant working in paddies, fields, and pastures with a slightly elevated radiation dose. It was physically exhausting work as we had to carry a heavy lead shielding cylinder to accurately measure radiation levels by excluding background radiation. Our study also coincided with the rainy season, so the soil in the fields turned to slush, and we would occasionally lose our footing. It was so tiring that on the first day when we arrived back at our accommodation base I climbed straight into my futon and slept.

When I was measuring radiation levels, the numbers on the dosimeter I carried with me were a constant reminder of the radiation fear. It felt as though radiationthe so-called "invisible fear"-was there right in front of my eyes. The abandoned, overgrown pastures and the unplowed fields seemed out of place even to me, a stranger viewing them for the first time. And people were living in this environment. Seeing that made me realize for the first time that we really were in a disaster area. In between times of work, I also had the opportunity to talk to Tamano's farmers, who helped us with our study. Speaking directly with the people involved gave a far more vivid picture of what was going on in the disaster zone than reports on television and other media. Just hearing real stories of the disasters moved me to tears. And the sight of the farmers battling to continue farming under such harsh conditions made a deep impression on me. I cannot forget the words of one farmer who told me that he hoped they would be able to starting farming again the following year. 
The March 2011 disasters caused a range of unprecedented problems, including economic damage from negative reputation. As a consequence, restoration of the farmland alone will not be sufficient for agriculture to recover. In addition to rehabilitating agricultural land, we must consider what can be done to conquer reputational damage and allow people to once again buy produce from the affected regions with peace of mind. Participation in the Soma Project served as the first step for students such as I to encounter these problems firsthand, form our own opinions, and consider what we can do to help.

Although Tokyo University of Agriculture runs other programs to assist the affected regions, the Soma Project is focused especially on agricultural recovery. Among various initiatives, the Soma Project is particularly characteristic of the university, and is a program in which students can feel that their efforts are helping revitalize the affected region. There are not many opportunities for students to experience firsthand the agriculture, conditions, and lives of people in the disaster zone, and I believe it is the perfect opportunity for those wanting to make a contribution to the region's revival. I hope that the recovery keeps moving forward, step by step, and I want to keep doing whatever I can to help as a volunteer-no matter how small my role may be.

Open Access This chapter is distributed under the terms of the Creative Commons Attribution Noncommercial License, which permits any noncommercial use, distribution, and reproduction in any medium, provided the original author(s) and source are credited. 